\title{
Spatial urban health equity indicators - a framework-based approach supporting spatial decision making
}

\author{
J. Flacke ${ }^{1} \&$ H. Köckler ${ }^{2}$ \\ ${ }^{1}$ Faculty of Geo-Information Science and Earth Observation (ITC), \\ University of Twente, The Netherlands \\ ${ }^{2}$ School of Spatial Planning, TU Dortmund University, Germany
}

\begin{abstract}
Aspects of urban health have nowadays become a central issue in many sustainability concepts and plans. Especially health equity issues play an important role in urban areas, because "where in a city you live and how that city is governed can determine whether or not one benefits from city living". That means differences in health outcome are amongst others determined by contextual factors. Scholars therefore detect a need for new urban health equity indicators that allow to monitor health inequities across place and time, particularly within a city neighbourhood. Likewise, population health is also more and more central in urban planning interventions striving for sustainable and healthy city development. However, in order to affect health issues by means of planning interventions, a good understanding of environmental and societal drivers and determinants of health outcomes, that can be influenced by interventions from planning and public health, is crucial. In the paper we develop an indicator framework to be used for targeting spatial planning interventions aiming for more urban health equity. The framework for Spatial Urban Health Equity Indicators (SUHEI) allows to map the relationships between exposure and health effects determined by various drivers, and therefore reveals explicit entry points for interventions. It combines elements of cause-effect indicator frameworks with elements of health equity models. First examples of the SUHEI framework as elaborated for the case study of the city of Dortmund in Germany. Results provide different entry points for urban planning interventions to contribute to more just and sustainable cities.
\end{abstract}

Keywords: environmental health, urban heath equity, Dortmund, indicators. 


\section{Introduction}

Traditionally urban planning has had a strong focus on health issues [1-3]. One goal of planning was to provide more or less healthy living conditions for the rapidly growing cities during industrialization since the $19^{\text {th }}$ century. Nowadays we see this primal vision of planning having a strong renaissance. Several studies and publications related to health issues stress the importance of place and space in health related research $[4,5]$ and the need for a better integration of public health and spatial planning [6-8].

Environmental health studies address physical, chemical, biological, and social factors external to a person that can potentially affect health. A common distinction is made between chemical factors, e.g. benzene, mercury, polycyclic aromatic hydrocarbons, and non-chemical factors e.g. pollen, noise, microwave radiation, unsafe neighbourhoods, unemployment [9]. Newer studies do not only consider such environmental burdens but extend also to environmental benefits, such as availability and accessibility of green areas [10]. From a spatial planning perspective especially those factors are of relevance, that can be regulated - among other - by means of spatial planning. These are the non-chemical factors having a discrete spatial characteristic, e.g. green or industrial areas, buildings, but also spatial processes, contributing to chemical as well as non-chemical factors, e.g. industrial sites or motorized transport resulting in noise, but also $\mathrm{PM}_{10}$ or $\mathrm{NO}_{\mathrm{x}}$ emissions.

Within environmental health studies special attention is paid to health equity issues. The question is investigated whether or not environmental benefits and burdens affecting health are spatially equally distributed over an area resp. among (subgroups of) a population or not. Population based studies take into account the social determinants of health, such as income, ethnicities, welfare, or payments $[11,12]$. The Rainbow model of Dahlgren and Whitehead [13] on the determinants of health shows various spheres of social and economic life and the wider environment having an impact on health of individuals, stressing that all these spheres are themselves affected by the changes in the built environment in complex and interacting ways [11]. Adding a normative standpoint [14] to the analysis of spatial inequities allows also to map health related environmental injustices $[15,16]$.

Health equity issues play an important role particularly in urban areas, because "where in a city you live and how that city is governed can determine whether or not one benefits from city living" [17]. Scholars therefore detect a need for new urban health equity indicators that allow to monitor health inequities across place and time, particularly within a city neighbourhood [18]. Such indicators need to be spatial in kind to support the development of place based policies, need to be measurable and linked to datasets, ideally highlight associations between the various determinants of health impacts, and allow measuring cumulative impacts from multiple environmental burdens or benefits.

Objective of the paper is to develop and map a set of indicators for analysing urban health inequities using the case study of the city of Dortmund in Germany. In doing so we suggest a suitable indicator framework (section 3) based on 
explanatory models of environmental health equity (section 2), suggest a number of indicators for the case study area and maps selected indicators (section 4). Results provide different entry points for urban planning interventions to contribute to more just and sustainable cities (section 5).

\section{Models for developing urban health equity indicators}

Environmental health equity is influenced by a number of various social and environmental factors and drivers contributing to various health outcomes, which are mutually interrelated and eventually even cumulate to multiple health risks. For example, the environmental exposure for a worker in a waste factory is probably higher than for an office employee, while the wages might be higher for the employee. Therefore they have different opportunities on the housing market, what might result in a healthier living environment for the employee, building on the assumption that land price is correlating with environmental quality. Furthermore they might have different capacities for recreation concerning money available for holiday, or knowledge on the health-care system. As a result the worker may suffer from respiratory and/or cardiovascular disease and may have a lower life expectancy.

Consequently, developing urban health equity indicators requires a good conceptual understanding of interrelationships and driving factors that influence health. This helps developing not just single indicators representing relevant determinants but forming a system of indicators that allows to analyse relationships between drivers and to target spatial planning interventions with a desired outcome.

Two groups of models that explain drivers of environmental health can be distinguished: On the one hand we see a number of models focusing on cause effect relationships between the different drivers leading to various health outcomes [19]; on the other hand there are a number of models focusing on the description of factors determining environmental health equity [20].

Concerning the identification of interventions the most elaborated cause effect model is the Driving force-Pressure-State-Exposure-Effect-Action (DPSEEA) indicator framework [21]. This is an advancement of earlier models deriving from environmental and sustainability science such as PSR-model [22] and the DPSIR model [23]. The DPSEEA model structures determinants of health into Driving forces (anthropogenic), that motivate and push the environmental process involved, Pressure (on the environment), often through human occupation or exploitation of the environment, State of the environment, Exposure of to humans to environmental conditions, and health Effects resulting from exposure to the environmental hazard. For addressing these various factors Actions are included, which are policy interventions aiming at reducing or avoiding health effects [19].

The Multiple Exposures-Multiple Effects (MEME) model [24] is a further development of the DPSEEA model combining state, pressure, and exposure factors under the heading of exposure, because they are in practice often hard to distinguish [19]. The model further recognizes contextual factors such as social conditions, economic development, and demographics, that influence both 
exposure and health outcomes. Valuing the relevance of contextual factors Morris et al. [25] added a contextual 'bubble' to the DPSEEA model that is "particularly suited to represent the local or regional dimension in the relationship between the environment and health at population level". In doing so both models, by Morris et al. and the MEME-Model, open the door to include social inequality by integrating the socio economic class and other compositional and contextual factors. However, all models are spatially not explicit emphasising the importance of the various spatial scales only implicitly [26].

Another group of models is explicitly focusing on the relationship between social and environmental factors in their effects on health outcomes. These models originate from disciplines of public health, epidemiology, and social science. Depending on their disciplinary background the models are based either on a very narrow understanding of the concept of environment reduced to poisoning substances (epidemiology), or a broader understanding including all physical, chemical, and biological factors external to a person either as potential environmental stressors or resources.

The model by Voigtländer et al. [27] highlights the influence of various spatial scales on individual health outcomes. The model distinguishes three levels of influential factors. The macro-level comprises general factors describing living conditions. These influence inequities on the meso-level, which is located on the spatial scale of neighbourhoods. On the meso-scale social as well as environmental factors, the latter being composed of stressors and resources, are considered.

The model by Bolte et al. [20] interprets the individual socio-economic and socio-demographic situation, measured with factors such as income, education, but also age, gender, as the main driver for the local living conditions and the individual vulnerability. The former is divided into local stressors (e.g. pollution, heat, crime) and local resources (e.g. green areas, supportive social networks, health services). The individual vulnerability comprises individual stress (e.g. personal stress), individual health behaviour (e.g. smoking), and individual knowledge and coping capacities. Both components together determine the individual exposure.

\section{Spatial urban health equity indicator framework}

The following requirements can be derived for an indicator framework to be used for targeting spatial planning interventions aiming for more urban health equity based on what is discussed above. The indicator framework should be action oriented, i.e. the indicators need to allow targeting interventions. For this, a distinction into drivers, state, and exposure is useful. Another requirement in connection with targeting spatial interventions is that the indicators should allow a small-scaled representation, i.e. they need to be mapped at neighbourhood level. Therefore a definition is needed what makes a neighbourhood [27]. While GISoperations usually allow to aggregate environmental factors at any spatial scale, this is more problematic with respect to data for the social context. These are often only available for administrative units such as districts, which not necessarily represent a functional spatial unit. Furthermore, in order to compare situations 
between neighbourhoods and the overall city for analysing potential spatial inequities, indicator values need to be available on both levels. Finally, the framework shall include indicators representing a cumulative risk, resulting from multiple burden and/or benefits occurring at the same time in the same place.

Based on these requirements we suggest the framework for Spatial Urban Health Equity Indicators (SUHEI) as shown in figure 1. The framework combines elements of cause effect indicator frameworks with elements of health equity models. It is composed of two spatial levels distinguishing city and neighbourhood level for mapping indicators. While driving forces, such as traffic density, public spending, or urban development might occur on multiple spatial scales, state variables, including environmental and social factors, are captured in indicators on city as well as on neighbourhood level. Exposure variables finally are mapped on neighbourhood level.

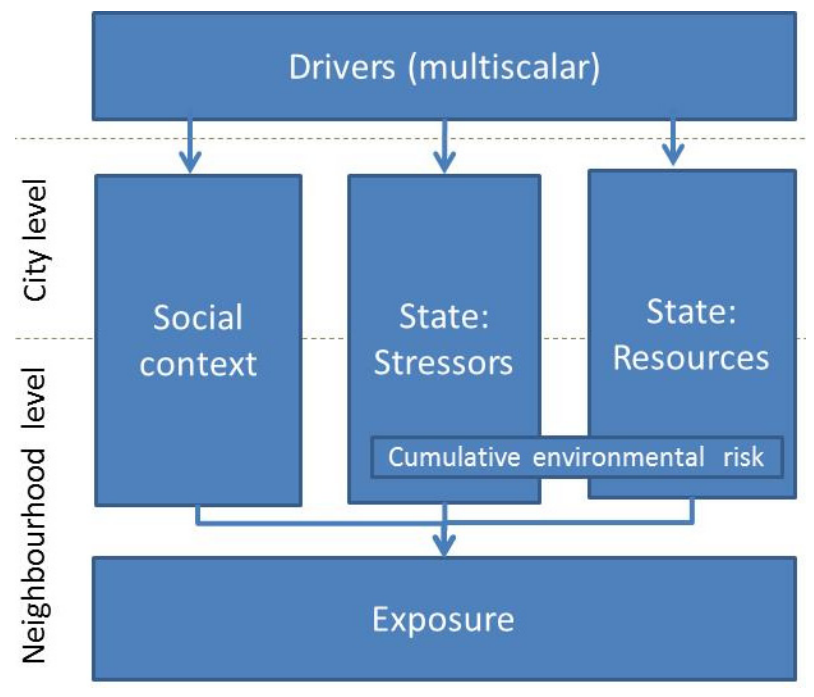

Figure 1: Spatial Urban Health Equity Indicator (SUHEI) framework.

Health outcome indicators are not included in the framework, although it is assumed that the improvement of the same is the main goal from a planning perspective. Instead, by including indicators based on strict cause effect relationships as derived from existing models, it is assured that health outcomes are addressed. Moreover, health data on neighbourhood level is hardly available. Likewise, the component of action, as included in the DPSEEA framework is not included in the framework, though it is meant to target interventions and the various state, driving forces, and exposure variables shall identify entry points for the same. In our understanding interventions are hardly captured as indicators, but identify certain planning activities to be taken (see section 5).

Environmental factors are divided into two groups of stressors and resources, the first one includes indicators like noise, air-pollution, odour, climate stress, but also crime or lack of health care provision. Resources represent factors having a 
positive health outcome, like green areas, sport facilities but also institutions or networks. A combination of these various stressors and resources, that might occur at the same time in the same place, is integrated as spatial indicators for cumulative environmental risks. The social context contains both factors for a vertical differentiation such as education attainment, income, employment status, and horizontal differentiation like age, gender, ethnic groups. Indicators for exposure are achieved by combining selected state variables with indicators of the social context, e.g. accessibility of green areas for children between 6 and 12 years per district.

Indicators for drivers, that influence both environmental resources and stressors as well as the social context, may exist on various multiple scales, from global to neighbourhood level (e.g. urban growth, motorized transport, national policies). They are important to be identified and included in the indicator framework, especially for interventions that are not end-of pipe solutions but following the precautionary principle. While they help understanding certain stressors and states these drivers are not always possible to be regulated by urban planning.

A crucial question is the delineation of neighbourhoods as spatial entities, for which the selected indicators shall be mapped. Ideally, the definition of spatial neighbourhood is flexible depending on functions and questions to be answered resp. interventions to be planned. Because (most) people spend their days in different settings, e.g. at home at school/work, for recreation, and therefore are exposed to various burdens and/or benefits within these settings. However, due to limited data availability, especially for the social context, often a compromise has to be found, resulting in mapping administrative units, for which socio-economic and socio-demographic data is available (e.g. a census tracts, wards, sub-districts). In any case, a potential limitation of the delineation of neighbourhood is the fact that these neighbourhoods are treated as islands when mapping environmental stressors and burdens (see modifiable areal unit problem (MAUP) [28]).

\section{Mapping of health related inequities: case study Dortmund}

For analysing health related inequities in a selected city the SUHEI framework needs to be locally contextualized, i.e. the focus in developing indicators is related to specific issues and problems in the case study area. Here, the city of Dortmund, Germany, is chosen as the case study area. The city is one of the case study cities of the research group Jufo-Salus ("The city as a healthy living environment independent of social inequalities", www.jufo-salus.de) which researches how cities can be shaped into a healthy living environment independent of health inequalities.

\subsection{Case study Dortmund in Germany}

The city of Dortmund $\left(280 \mathrm{~km}^{2}\right)$ is located in the western part of Germany in the former coal and steel production area called Ruhr Area. The city is home to nearly 600,000 inhabitants. Since the 1980 s Dortmund is going through a long-lasting economic transformation due to closing down of coal mines and steel production 
companies, resulting in a high unemployment rate $(12.9 \%$, in Germany $5.0 \%$ (2014)). As a result of the economic boost in the middle of the $20^{\text {th }}$ century Dortmund, similar to the other cities of the Ruhr Area, was then very attractive for migrant workers. Hence, today many people living in Dortmund are having a background of migration (almost 30\%).

\subsection{Selected spatial health inequities in Dortmund}

At the start of the Jufo-Salus research project a workshop with local stakeholders from health, planning, and environment was organized. Aim of this workshop was to identify locally specific problematic situations and conditions with respect to health inequities and to discuss potential indicators to map these inequities [29]. The following main issues were identified during the workshop: A typical characteristic of the living and housing conditions, especially in more deprived areas, are historically grown land use patterns exhibiting a close proximity of residential areas with other land uses such as industry and commercial. While these mixed land use structures are deemed to have benefits in terms of increasing vitality and liveability of a district, it is nowadays typically associated with and also having negative environmental impacts. The district of the Nordstadt, located north of the city centre, is probably the most deprived neighbourhood revealing such a structure. Here, also a god access to green areas and parks for recreation and leisure purposes is limited. Finally, statistical data shows that the district has a significantly higher percentage of migrant population and a lower average life expectancy, compared to other districts.

For developing urban health equity indicators the following topics were suggested during the workshop: (1) availability and accessibility of green areas, (2) mixed land use pattern resulting in high emissions in residential areas, (3) local transport in relation to pollution, mobility, and physical activity. Figure 2 suggests potential indicators applying the SUHEI framework for the topics of green areas and transport/pollution. In the following the topic of green areas will be elaborated as an example for application of the SUHEI framework.

Urban greenspace is a typical environmental resource having multiple positive health effects, which is therefore often included in environmental health studies [30]. From an equity perspective especially two aspects are of relevance with respect to urban greenspace: the availability of high quality greenspace in the neighbourhood (within walking distance to residential areas), and the spatial as well as social (safety issues) accessibility of the same. In relation to the social context, the availability and accessibility of greenspace for children between 6 and 14 is of special interest, because green areas provide a possibility for physical activity outside the house, which is nowadays, in time of increasing obesity among youth, and particular important aspect of health promotion.

The distribution of greenspace per district in Dortmund reveals a rather wide range (figure 3). While some districts, especially the densely built up areas in the city centre and other sub-centres, show an extremely low availability of green space of less than $8.5 \%$ of the entire area, some of the more peripheral, non-urban districts contain green space of 30 and $60 \%$, however the latter mainly being forest 


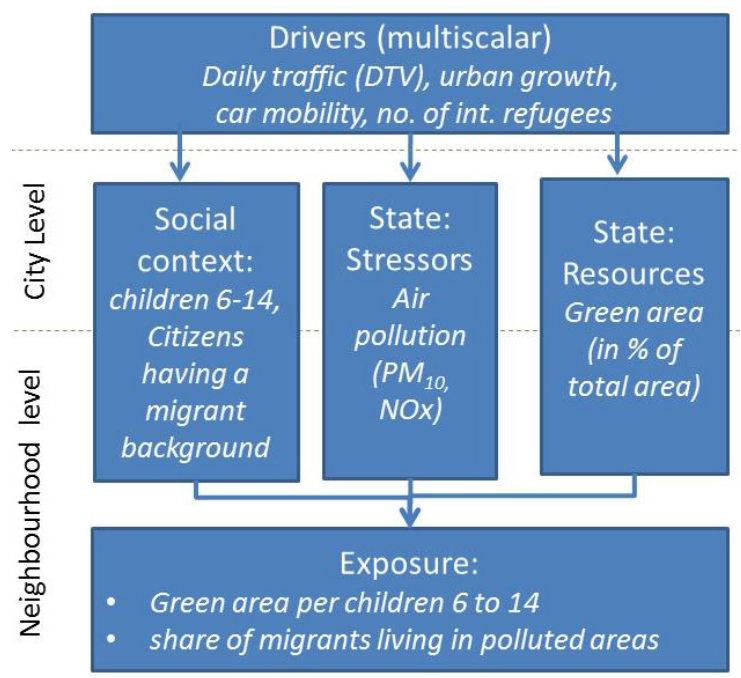

Figure 2: $\quad$ Selected indicators for Dortmund.

areas rather than urban parks. The three Nordstadt districts (Innenstadt Nord) north of the city centre are having a rather averaged provision of green space (between 11 and $20 \%$, city wide average $17.5 \%$ ), which is for such a densely urbanized residential area for the time being a reasonable result.

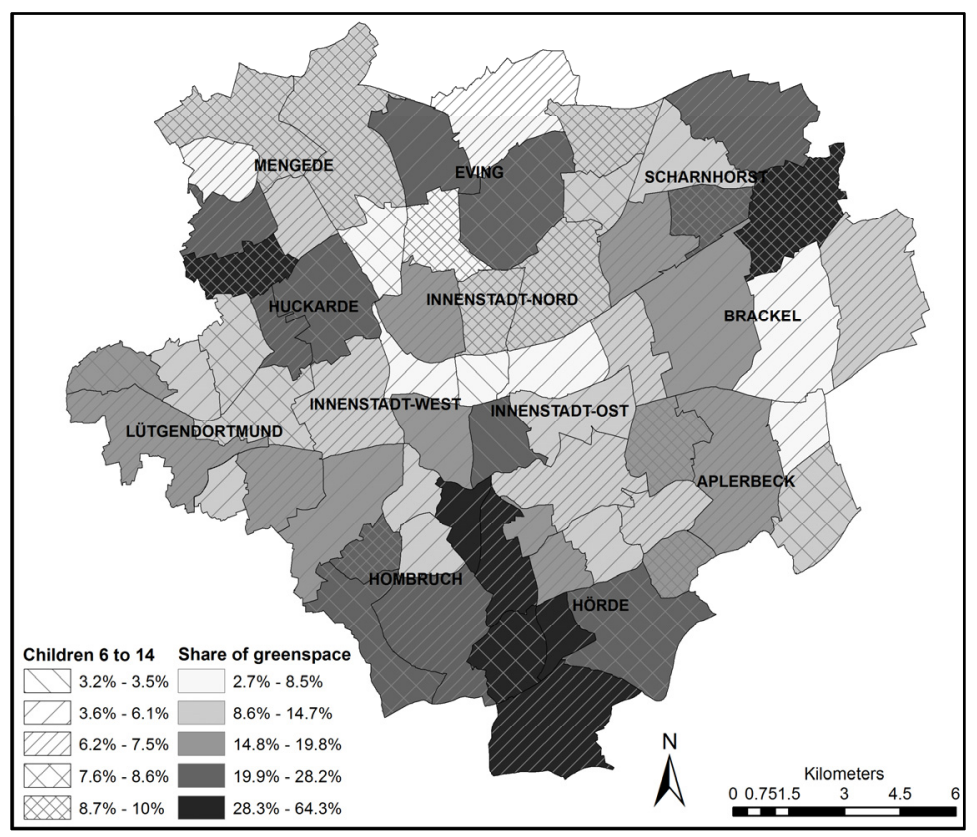

Figure 3: $\quad$ Share of greenspace and children aged 6 to 14 per district. 
With respect to the share of children between 6 and 14 of the entire population living in the different districts the results are more clearly. The city centre has, equal to its function as the main commercial centre and its low share of green area, the lowest density of children. Except for three small district in the southern half of the city, the vast majority of districts having a share of children aged 6 to 14 of more than $8.5 \%$ (city wide average $7 \%$ ) is located in the northern half of the city. Two of the three districts of the Nordstadt are the top district in terms of children density with $9.8 \%$ resp. $10 \%$. That means, the youngest population of Dortmund is living in the Nordstadt, which does not necessarily match with the lowest life expectancy rate here (see above), and needs to relate to the provision of green space for analysing eventual spatial inequities pointing at potential planning interventions.

A suitable exposure indicator would quantify such a relationship, based on eventual minimum standards of necessary provision of green space per child. From the map (figure 3 ) those districts would have to be selected showing a light grey colour for a minimal share of urban greenspace together with a narrow crosshatched pattern indicating a high density of children.

It needs to be mentioned that the presented analysis is only a first approach to apply the SUHEI framework, which includes a number shortcomings and limitations so far. The overlay of share of green with density of children aged 6 to 14 in figure 3 only says something about the principal availability of green space within the district, but nothing about the accessibility of the same for children. For such an analysis better information about the exact location of the green areas within the district and the location of the children would have to be taken into account. Furthermore, the spatial resolution of districts in figure 3 was done due to limited data availability on sub-district level, but is not sufficient to represent homogenous neighbourhoods of Dortmund.

\section{Conclusions: spatial decision making}

Indicators based on the SUHEI framework are means to the end of identifying urban planning interventions. The approach offers various opportunities for addressing health inequity more adequately than common in todays' planning routines. We illustrate this with an example from environmental planning. Here, commonly overall estimations of exposure or assumed impact on humans are identified [31], but single human beings or subgroups of population and their individual health status are not differentiated. The SUHEI framework offers a more specific information basis for doing so, by combining of environmental state indicators with indicators of the social context based on health equity models.

Information based on spatial indicators in the SUHEI framework provide direct input to various local plans and programmes. The share of green-space per children aged 6 to 14, differentiated in neighbourhoods as shown in figure 3, e.g. could be used as a priority in landscape or urban development plans. Information on exposure of migrants towards air emissions could be included in strategic environmental impact statements. 
Indicator maps overlaying different states of the environment with social context data focus on already planned and built up urban areas. They could be used for informing policies and programmes for inner urban development or urban regeneration for a more healthy urban development. In Germany the programme "Soziale Stadt" aims at improving living conditions in deprived neighbourhoods. The emerging debate on healthy cities includes recommendations to integrate health and environment in such programmes oriented towards deprived neighbourhoods [32]. The SUHEI model could provide a basis to underpin such recommendations and integrate them in urban planning routines.

\section{Acknowledgements}

We thank Jufo-Salus (Junior Research Group "The City as healthy living environment independent of social inequalities"): Technical University Dortmund, Faculty of Spatial Planning, Department of Urban and Regional Planning, Dortmund, Germany (Sabine Baumgart, Heike Köckler, Andrea Rüdiger, Raphael Sieber, Lisa Waegerle); University of Bremen, Faculty of Human and Health Sciences, Institute of Public Health and Nursing Research, Department of Social Epidemiology, Bremen, Germany (Gabriele Bolte, Ursula Hemetek, Steffen Schüle); University of Applied Sciences Fulda, Faculty of Caring and Health, Public Health Institute, Department of Health Promotion, Fulda, Germany (Beate Blättner, Ursula Hemetek).

We thank the City of Dortmund for providing the spatial and statistical data sets used in this study within the cooperation agreement for the Jufo-Salus.

\section{References}

[1] Rodenstein, M., Stadtplanung und Gesundheit - ein Rückblick auf Theorie und Praxis. Handbuch Stadtplanung und Gesundheit, ed. C. Böhme, C. Kliemke, B. Reimann, W. Süß, Verlag Hans Huber: Bern, pp. 15-25, 2012.

[2] Howard, E., Gartenstädte von morgen: Das Buch und seine Geschichte, Ullstein: Berlin 1968.

[3] Le Corbusier. Le Corbusiers "Charta von Athen": Texte und Dokumente, Vieweg: Braunschweig, 1988.

[4] Cummins, S., Curtis, S., Diez-Roux, A.V., Macintyre, S., Understanding and representing 'place' in health research: a relational approach. Soc Sci Med, 65(9), pp. 1825-1838, 2007.

[5] Macintyre, S., Ellaway, A., Cummins, S., Place effects on health: how can we conceptualise, operationalise and measure them? Soc Sci Med, (55), pp. 125-139, 2002.

[6] Barton, H., Grant, M., Urban Planning for Healthy Cities: A review of the progress of the European Healthy Cities Programme. J Urban Health 90(S1), pp. 129-141, 2013.

[7] Abernethy, P., Bridging conceptual "silos": bringing together health promotion and sustainability governance for practitioners at the landscape scale. Local Environment, pp. 1-25, 2014. 
[8] Corburn, J., Toward the healthy city: People, places, and the politics of urban planning, MIT Press: Cambridge; Mass., 2009.

[9] Sexton, K., Linder, SH., The Role of Cumulative Risk Assessment in Decisions about Environmental Justice. IJERPH , 7(11), pp. 4037-4049, 2010.

[10] Kruize, H., On environmental equity: Exploring the distribution of environmental quality among socio-economic categories in the Netherlands, Koninklijk Nederlands Aardrijkskundig Genootschap: Utrecht, 2007.

[11] CSDH (Commission on Social Determinants of Health), Closing the gap in a generation: Health equity through action on the social determinants of health; final report. Geneva, 2008.

[12] Bolte, G., Pauli, A., Hornberg, C., Environmental justice - Social disparities in environmental exposures and health. Overview. Encyclopedia of environmental health, ed. J.O. Nriagu, Elsevier Science: Amsterdam, London, pp. 459-70, 2011.

[13] Dahlgren, G., Whitehead, M., Policies and strategies to promote social equity in health. Background document to WHO - Strategy paper for Europe. Geneva: Institute for Future Studies; 2007.

[14] Walker, G.P, Environmental justice: Concepts, evidence and politics, Routledge: London, New York, 2012.

[15] Barzyk, T.M., White, B.M., Millard, M., Martin, M., Perlmutt, L.D., Harris F., et al., Linking Socio-Economic Status, Adverse Health Outcome, and Environmental Pollution Information to Develop a Set of Environmental Justice Indicators with Three Case Study Applications. Environmental Justice, 4(3), pp. 171-177, 2011.

[16] Raddatz, L., Mennis, J., Environmental Justice in Hamburg, Germany. The Professional Geographer; 65(3), pp. 495-511, 2013.

[17] WHO \& UN Habitat, Hidden cities: unmasking and overcoming health inequities in urban settings, Geneva, 2010.

[18] Corburn, J., Cohen, A.K., Why We Need Urban Health Equity Indicators: Integrating Science, Policy, and Community. PLoS Med, 9(8), pp. 1-6, 2012.

[19] Hambling, T., Weinstein, P., Slaney, D., A Review of Frameworks for Developing Environmental Health Indicators for Climate Change and Health. Int. J. Environ. Res. Public Health, (8), pp. 1-22, 2011.

[20] Bolte, G., Voigtländer, S., Razum, O., Mielck, A., Modelle zur Erklärung des Zusammenhangs zwischen sozialer Lage, Umwelt und Gesundheit. Umweltgerechtigkeit: Chancengleichheit bei Umwelt und Gesundheit: Konzepte, Datenlage und Handlungsperspektiven, ed. G. Bolte, G. Bunge et al., Verlag Hans Huber: Bern, pp. 39-50, 2012.

[21] WHO, Environmental health indicators. Framework and methodologies. Geneva, 1999.

[22] OECD, OECD Core Set of Indicators for Environmental Performance Reviews - A Synthesis Report by the Group on the State of the Environment, 1993. 
[23] Smeets, E., Weterings, R., Environmental indicators: Typology and overview: EEA; 1999.

[24] Briggs, D., Making a Difference: Indicators to Improve Children's Environmental Health, 2003.

[25] Morris, G., Beck, S., Hanlon, P., Robertson, R., Getting strategic about the environment and health. Public Health; (120), pp. 889-903, 2006.

[26] Köckler, H., Flacke, J., Health-related inequalities in the global north and south - A framework for spatially explicit environmental justice indicators. Proceedings of the 14th N-AERUS / GISDECO conference, Enschede, 2013.

[27] Voigtländer, S., Mielck, A., Razum, O., Die Bedeutung des kleinräumigen Kontexts für Gesundheit: Entwurf eines Erklärungsmodells. Gesundheitswesen, 74(11), pp. 702-709, 2012.

[28] Openshaw, S., The modifiable area unit problem, Norwich, 1984.

[29] Jufo-Salus, Gesundheitsfördernde Stadtentwicklung für Alle in Dortmund: Die Jufo-Salus im Dialog mit Dortmunder Akteuren: Dokumentation des Workshops zu Themen und Indikatoren vom 10. September 2013. Dortmund, 2013.

[30] Krekel, C. et al., The Greener, The Happier? The Effects of Urban Green and Abandoned Areas on Residential Well-Being. Berlin. SOEP papers 728, 2015.

[31] Köckler, H., Environmental Justice - aspects and questions for planning procedures. UVP report; 28(3+4), pp. 139-142, 2014.

[32] Umwelt- und Gesundheitsaspekte im Programm Soziale Stadt - Ein Plädoyer für eine stärkere Integration: Positionspapier aus der ARL, 2014. http://shop.arl-net.de/media/direct/pdf/pospaper_97.pdf. 